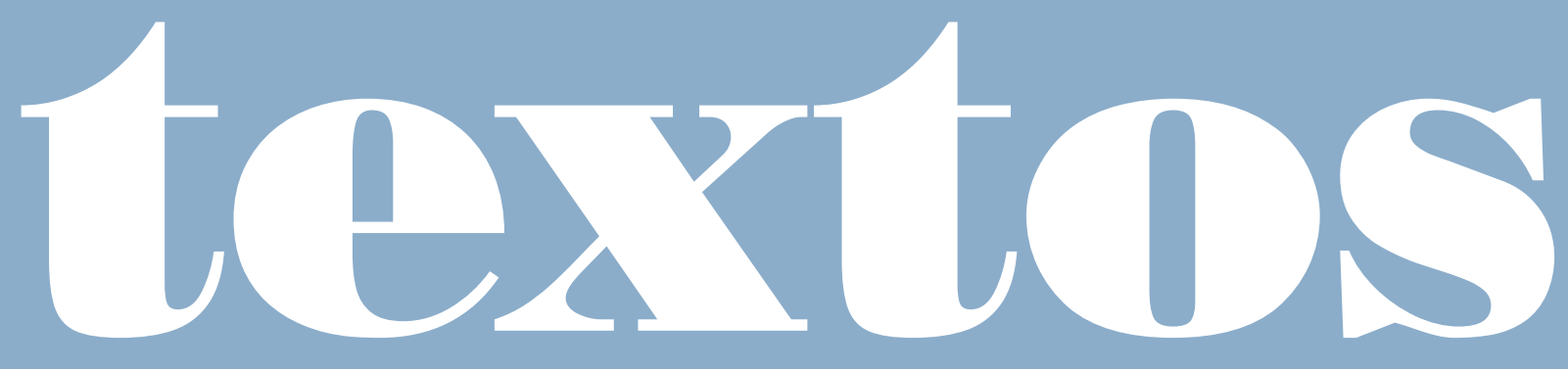





\title{
Prata que vale ouro
}

\author{
José de Paula Ramos Jr.
}

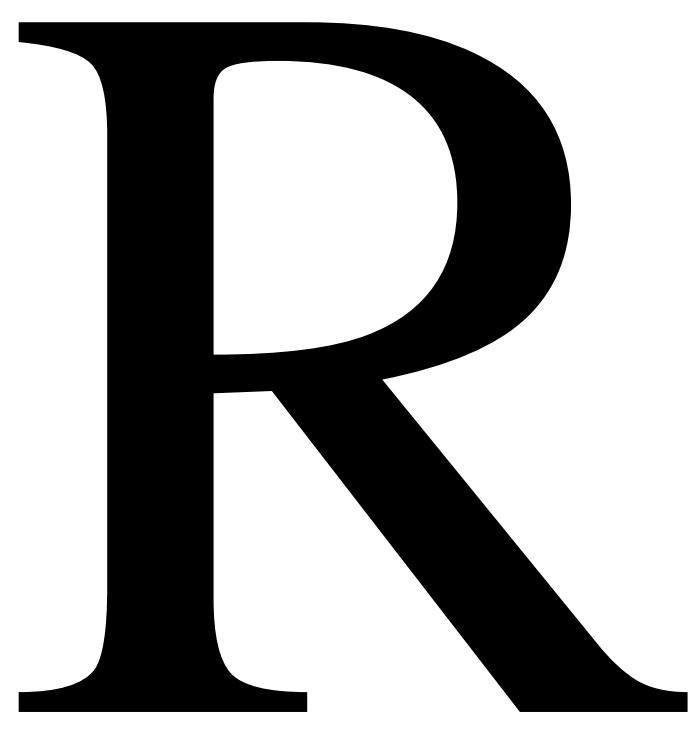

ANULFO HORA PRATA nasceu em 1896 no município de Lagarto, estado de Sergipe. Cursou medicina em Salvador e no Rio de Janeiro, onde se formou em 1919. Foi médico, entre outras, nas cidades de Aracaju e Mirassol, esta no interior de São Paulo, até fixar residência em Santos, onde dirigiu o serviço radiológico da Santa Casa e da Beneficência Portuguesa. Nesses hospitais, bem como em sua clínica particular, construiu sólida reputação profissional e, com espírito de caridade cristã, acompanhou o drama de pacientes que buscavam tratamento para a tuberculose, muitos deles estivadores e operários a serviço do porto.

Com a esposa, a professora Maria da Glória Brandão, teve um único filho, Paulo, nascido em Mirassol em 1924. Três anos depois, a família se estabeleceu em Santos, onde o autor viveu até sua morte, ocorrida na cidade de São Paulo, aos 46 anos de idade, em 24 de dezembro de 1942.

JOSÉ DE PAULA RAMOS JR. é professor do Departamento de Jornalismo e Editoração da ECAUSP e autor de, entre outros, Leituras de Macunaíma: Primeira Onda (1928-1936) (Edusp/Fapesp). 
A biblioteca particular de Ranulfo Prata constituída de aproximadamente 1.200 volumes, entre os quais se destacam algumas raras primeiras edições de literatura francesa, portuguesa e brasileira - foi doada pela viúva ao Itamaraty em 1960. Esse acervo, chamado Coleção Ranulfo Prata, foi organizado por Paulo de Carvalho Neto, sobrinho e afilhado do escritor, e integrado ao núcleo básico do Centro de Estudos Brasileiros de Quito, no Equador.

A carreira de escritor teve início auspicioso: estudante de medicina em Salvador, o jovem Ranulfo Prata vence, com o conto "O Tropeiro", um concurso literário promovido pelo jornal baiano A Tarde, em 1916. Dois anos depois, prestes a concluir os estudos na Faculdade de Medicina do Rio de Janeiro, publica seu primeiro livro, o romance $O$ Triunfo (1918), saudado pelo crítico Jackson de Figueiredo, líder católico que se tornaria amigo do escritor estreante:

"É evidentemente impossível negar méritos de inteligência a quem, tão moço ainda, aparece, em tal meio, não com um livrinho de versos, mas tentando um gênero realmente difícil e, por último, quase abandonado entre nós. No Brasil contemporâneo, os romancistas de verdade não ultrapassarão talvez a cinco ou seis. Rodolfo Teófilo e Papi Júnior, no Ceará, a grande figura de Xavier Marques, na Bahia, Afrânio Peixoto, Coelho Neto e Lima Barreto, aqui no Rio, Veiga Miranda, em S. Paulo, são aqueles de que me lembro agora" (Figueiredo, 1918 apud Carvalho Neto, 1972).

O crítico lisonjeia o romancista ao incluí-lo, indiretamente, no rol dos "romancistas de verdade", entre os quais distingue Lima Barreto, que também se pronunciou sobre $O$ Triunfo, nos seguintes termos:

"É um romance, antes, uma novela em que o autor revela grandes qualidades para o gênero. Já possui a sobriedade de dizer, a naturalidade do diálogo e não limalha a frase estafadamente. [...] Com tantas e superiores qualidades, é de esperar que o Sr. Ranulfo Prata venha a ser um grande romancista. [...] Tive com a leitura de seu livro o máximo prazer e espero que ele se repita em um segundo livro que, em breve, estou certo, ele nos dará" (Barreto, 1918 apud Carvalho Neto, 1972).
O segundo romance de Ranulfo Prata - Dentro da Vida — é lançado em meados de 1922 e não sabemos se Lima Barreto o pôde ler antes de sua morte, ocorrida em novembro desse mesmo ano. Todavia, os dois escritores mantiveram uma amizade fraterna desde que se conheceram, em 1918, após a publicação de $O$ Triunfo. Como se sabe, o jovem médico, ciente da precária saúde do ficcionista carioca, associada ao alcoolismo, convida o enfermo, em 1921, para uma temporada em Mirassol, onde se esforça para afastá-lo da bebida, mas em vão. Nas crônicas "Até Mirassol (Notas de Viagem I, II e III)", "Dias da Roça" e "Generosidade", recolhidas postumamente no livro Marginália, Lima Barreto (1953) se refere a essa passagem pelo norte de São Paulo. Seja como for, na recepção crítica a $O$ Triunfo, o autor de $O$ Triste Fim de Policarpo Quaresma observa traços estilísticos de Prata que, cada vez mais depurados, seriam reconhecidos e louvados por outros críticos em Dentro da Vida e em obras posteriores. Segundo o erudito João Ribeiro (1922 apud Carvalho Neto, 1972), da Academia Brasileira de Letras:

"Todas as páginas do livro [Dentro da Vida] até esse momento são fortes e encantadoras e talvez as melhores do romance que é de grande correção de forma e simplicidade de entrecho. [...] A primeira parte do livro é a melhor, sob todos os aspectos; e não só a melhor, é excelente como ideação e expressão próprias de um verdadeiro romancista".

Em uma resenha estampada na Revista do Brasil, quando dirigida por Júlio de Mesquita e Monteiro Lobato, o crítico enfatiza aquelas qualidades apontadas nas citações anteriores e também reconhece em Dentro da Vida o notável talento de Ranulfo Prata para o gênero romanesco:

"Eis aqui uma obra que dá gosto bibliografar. Excelente por todos os motivos, sincera, rica de todas as qualidades que fazem de um livro algo mais que papel impresso com palavras de engenhoso arranjo. [...] Estilo correntio, sem defeitos, sem arrebiques, todo plasmado nessa simplicidade que é o segredo de todos os verdadeiros escritores. Ranulfo Prata é, em suma, um perfeito artista do romance e há tudo que esperar de sua sensibili- 
dade de eleito e de sua pena pura de amaneirados ou vícios da moda" (in Dentro da Vida, s.d. apud Carvalho Neto, 1972).

Não foi possível apurar a autoria dessa resenha, mas não nos parece um disparate a hipótese de Monteiro Lobato a ter redigido, por certos índices característicos de seu estilo - como a clareza, a objetividade, o toque irônico, a simplicidade da escolha lexical "sem arrebiques", a sintaxe "correntia" - e dos valores estéticos preconizados por ele e que o definem como autor moderno, mas antimodernista, como se pode entrever na censura aos "amaneirados ou vícios da moda". Se assim for, o crítico parece se reconhecer no estilo do resenhado, sem nenhum prejuízo para a personalidade artística deste ou daquele. Se assim não for, será, ao menos, legítimo supor que a obra de Ranulfo Prata alinha-se à corrente literária conhecida como pré-modernismo, que, a despeito da denominação um tanto vaga e, mesmo, imprecisa, tem o mérito de reconhecer afinidades entre autores díspares como Graça Aranha, Euclides da Cunha, Lima Barreto e o próprio Monteiro Lobato, todos herdeiros do realismo do século XIX. Assim também Ranulfo Prata, cujas obras imediatamente seguintes a Dentro da Vida vinculam-se a essa tradição, agora explorando o veio regionalista: o livro de contos A Longa Estrada e o romance $O$ Lírio na Torrente, ambos lançados em 1925 pela editora carioca Anuário do Brasil. O Lírio na Torrente receberia o prêmio de melhor romance da Academia Brasileira de Letras em 1926.

O regionalismo dessas duas obras, porém, superaria a mera notação do pitoresco, como assinala Alceu Amoroso Lima sob o pseudônimo de Tristão de Ataíde (1925 apud Carvalho Neto, 1972): “o sr. Ranulfo Prata mostra como realmente não é necessário limitar-se ao pitoresco localista para criar regionalismo de boa espécie".

O filólogo Silveira Bueno, em sua resenha ao romance $O$ Lírio na Torrente, acentua as qualidades superiores de Ranulfo Prata na construção da trama e do efeito impactante da narrativa: "A força narradora de Ranulfo Prata surge do conjunto todo, do poderoso arquitetamento da obra inteira, onde nada é despiciendo, onde tudo é necessário para o desfecho profundo, inesquecível, humano, dos romances que escreve".
A obra seguinte de Ranulfo Prata - Lampião (1934) - permanece na esfera regionalista das anteriores, mas não é, propriamente, uma obra de ficção. O jornalismo cultural da época vale-se, sobretudo, da noção de documentário para caracterizar o livro lançado pela Editora Ariel em 1934, como se vê, por exemplo, em nota do periódico Correio de São Paulo (1934 apud Carvalho Neto, 1972): "Lampião deve ser considerado como o mais perfeito documentário jamais publicado no Brasil sobre o banditismo do Nordeste". Lampião tem interesse artístico, sem dúvida, mas seria, mais propriamente, um precursor do gênero conhecido, hoje, como jornalismo literário. Nesse sentido, as propriedades estéticas do texto estão a serviço de um tema da realidade, e não de uma narrativa de ficção - a questão do cangaço no Nordeste abordado numa perspectiva que se aproxima da análise histórica e sociológica, mas sem compromisso com o texto acadêmico, antes, configurando uma prática discursiva cuja linguagem se encontra na fronteira entre o registro jornalístico e o literário. Assim, o jornal A Nação o reconhece como um gênero híbrido: "uma completa reportagem literária sobre o famoso bandido nordestino" (grifo meu). Neste e em outros aspectos, o livro se aproxima de Os Sertões, como assinala Lívio Xavier (apud Carvalho Neto, 1972), mas para lamentar a influência: "O autor é mais uma das vítimas inumeráveis de Euclides da Cunha”. A despeito dessa reserva, certamente determinada pelo gosto e pelas afinidades intelectuais do articulista, a observação procede, pois há semelhanças notáveis entre Lampião, de Ranulfo Prata, e Os Sertões, de Euclides da Cunha. Mais uma vez, mostra-se pertinente a hipótese segundo a qual a produção de Ranulfo Prata vincula-se à tradição realista do século XIX, regionalista ou não, tal como se verifica no denominado pré-modernismo.

Todavia, isso será válido quanto à obra publicada até 1934, pois o último livro do escritor, Navios Iluminados (1937), configura um notável exemplo do "romance de 1930". O pesquisador Luís Bueno (2006, pp. 84-5) assinala a presença precoce de certos aspectos dessa corrente no segundo romance de Ranulfo Prata - Dentro da Vida (1922) —, como o "tom de depoimento [...] uma surpreendente economia de expressão e sentimento [...] a preferência por uma pobreza quase 
nunca poetizada [...] o conflito entre campo e cidade [...], o registro do cotidiano de um lugarejo do interior". Faltava-lhe, porém, a "referência aos processos de exploração econômica" (Bueno, 2006, p. $85)$, característica marcante do romance social da década de 1930, desde sua manifestação, em 1928, no "precursor oficial" da corrente neorrealista, $A$ Bagaceira, de José Américo de Almeida.

Em Navios Iluminados isso não falta. A mó do capitalismo reifica, desgasta e, literalmente, esmaga operários do porto de Santos, palco ficcional da ação do romance. Contudo, isso se dá sem qualquer transposição mecânica de material extraliterário para a ficção. Ao contrário, o elemento externo torna-se interno e se integra "organicamente" à estrutura da obra, como recomenda Aristóteles (1973), entre tantos ilustres teóricos da narrativa.

A lógica do capitalismo não se apresenta de modo ostensivo, e não se explicita, quer na enunciação, quer no enunciado, qualquer sombra de "mensagem" política com alguma solução para as contradições da luta de classes. Esta é encenada de modo motivado, entranhada na vida do protagonista, o estivador Severino, e de seus companheiros de infortúnio cujo cotidiano se condensa na teia de episódios urdidos de modo a configurar aquele efeito de documentário, típico do romance social da década de 1930.

As mazelas dos operários das Docas de Santos e a vida tão sofrida de famílias pobres do bairro do Macuco articulam-se à trajetória trágica de Severino, migrante nordestino que abandona sua minúscula e estéril propriedade rural no sertão baiano, bem como a sua família, em busca de trabalho no rico Sudeste do Brasil, para nele encontrar também fome, miséria, humilhação, doença e desespero.

O narrador, discreto, não interfere na ação, não a comenta, não tece digressões. Todavia, combina-se esse distanciamento com a perspectiva onisciente do narrador em terceira pessoa, que apresenta os fatos e os ambientes exteriores e interiores, bem como a ação interior - pensamentos, sentimentos e sonhos, não só do protagonista -, em enunciados de máxima economia de imagens e palavras, mas de grande efeito plástico, de cunho algo expressionista. Hábil, o narrador sabe explorar a variação de planos (geral, de conjunto, médio ou close-up), em que o foco ora se aproxima, ora se afasta, contribuindo para tornar a ação empolgante e comovente. Assim, a narrativa, na movimentação rápida ou lenta, apresenta um caráter entre épico e lírico. O lirismo, todavia, não manifesta ilusões nem expressa sentimentalismo; ao contrário, mostra-se desencantado, às vezes áspero, outras seco ou amargo, sem deixar de ser pungente. O elemento épico transparece, sobretudo, na dinâmica da ação não de heróis ilustres, mas de obscuros proletários, debilitados e incapacitados para o trabalho, quer nos porões de navios, nos armazéns ou nas oficinas em que trabalham, quer nas moradias insalubres que habitam - a maior parte delas, vivendas coletivas em chalés de madeira, quartos de pensão ou mesmo infectos porões alugados.

Ressalte-se, entre as qualidades da enunciação e do enunciado, o estilo conciso, simples e claro de um registro culto que absorve a riqueza expressiva de variantes da linguagem popular, de modo a contribuir para a construção de um efeito de sentido que sugere naturalidade e sinceridade, além de reforçar o efeito de verossimilhança ao encenar a crônica do degradante cotidiano dos trabalhadores das Docas de Santos e das famílias pobres do bairro do Macuco.

Entre outros críticos, Nelson Werneck Sodré (1938 apud Carvalho Neto, 1972) saudou os dotes de Ranulfo Prata como romancista, já notáveis em obras anteriores, mas que teriam chegado à plenitude no então recém-lançado Navios Iluminados. A essa plenitude, no entanto, seguiu-se o silêncio, pois o autor morreria, em 1942, como já foi dito, aos 46 anos de idade, sem publicar outra obra.

Paulo de Carvalho Neto (1972), no ensaio "Um Lugar para Ranulfo Prata", que inclui uma importante "contribuição bibliográfica" aos estudos do autor e de sua obra, observa o descompasso entre a reputação obscura e o valor do escritor que, embora lido e favoravelmente acolhido por críticos como, entre outros, João Ribeiro, Alceu Amoroso Lima, Agripino Grieco e Nelson Werneck Sodré, fora esquecido por "tantos outros autores responsáveis por darem forma orgânica ao patrimônio literário brasileiro", mas que, "não obstante, incluem e resenham obras de alguns autores que não resistiriam a um estudo comparado com a produção de Ranulfo Prata" (Carvalho Neto, 1972).

Se houve injustiça, ela certamente foi em parte reparada pela dissertação de mestrado História e Literatura no Porto de Santos: O Romance de 
Identidade Portuária "Navios Iluminados", de Alessandro Alberto Atanes Pereira*, e pelo destaque dado à obra do escritor sergipano em Uma História do Romance de 30, de Luís Bueno, em que o estilo de Navios Iluminados é comparado, "em suas linhas gerais e a despeito das inevitáveis diferenças" (Bueno, 2006, p. 494), ao de Graciliano Ramos:

"Navios Iluminados é um romance estruturado sobre essa nova visão desesperançada que começa a dominar no final da década [de 1930]. Esse movimento pendular - que, como se verá, está também na base da estrutura do mais importante romance do final da década (e talvez de toda a década), Vidas Secas —, entranhado no desenvolvimento das ações do romance, dá uma representação artística exemplar ao espírito daqueles anos em que uma guerra decisiva parece inevitável e os ideais que pensavam uma sociedade pós-liberal justa têm que ser adiados" (Bueno, 2006, p. 503).

É, ainda, de Luiz Bueno o comentário que, de certo modo, reitera a observação de Paulo de Carvalho Neto quanto ao injustificado esquecimento de Ranulfo Prata no cenário da literatura brasileira:

" Disponível em: http://www.teses.usp.br/teses/disponiveis/8/8138/tde-30092008-145514/pt-br.php.
"Navios Iluminados é um dos mais significativos romances do final da década [de 1930]. Embora não tenha tido nada do sucesso de Os Corumbas - e em grande medida porque o romance social entusiasmava menos nesses tempos de dúvida que ele próprio contribui para definir -, o romance de Ranulfo Prata tem todas as suas qualidades, acrescidas da escrita madura de um autor já veterano, que conhecia bem seus meios de expressão. Embora não seja um livro de todo desconhecido — já teve três edições, a última de 1996 — permanece menos lido do que deveria ser".

Em sua aguda crítica, o juízo de Luiz Bueno reconhece a importância e a excelência de Navios Iluminados, mas há um pequeno reparo a fazer. A obra-prima de Ranulfo Prata, afora uma edição argentina, traduzida para o espanhol, recebeu quatro e não três edições brasileiras: a primeira (1937), da José Olympio; a segunda (1946), do Clube do Livro; a terceira (1959), da Edições O Cruzeiro; a quarta (1996), da Editora Scritta em parceria com a Prefeitura Municipal de Santos.

A coleção Reserva Literária, projeto de edições fidedignas da editora-laboratório Com-Arte, da ECA-USP, em parceria com a Edusp, prepara a quinta edição desse romance extraordinário, que será lançada em 2014. Espera-se que ela também contribua para a ampliação do prestígio desse escritor tão admirável — Prata que vale ouro - junto aos leitores de hoje. 


\section{BIBLIOGRAFIA}

ARISTÓTELES, Poética. Tradução, comentários e índices analítico e onomástico de Eudoro de Souza. São Paulo, Abril Cultural, 1973 (Os Pensadores, vol. IV).

BARRETO, Lima. "O Triunfo", in ABC, Rio de Janeiro, 28/set./1918. . Marginália, São Paulo-Rio de Janeiro, Mérito, 1953.

BUENO, Luís. Uma História do Romance de 1930. São Paulo/Campinas, Edusp-Editora da Unicamp, 2006.

BUENO, Silveira. "Livros Novos. O Lírio na Torrente", in Folha da Noite, São Paulo, 11/out./1925.

CARVALHO NETO, Paulo de. "Um Lugar para Ranulfo Prata", in Revista do IEB. São Paulo, no 12, 1972, pp. 171-90. Disponível em: www.ieb.usp.br/publicados/doc/ rieb12_1349115221.pdf. Acesso em: 10/5/2013.

"DENTRO da Vida", in Revista do Brasil, São Paulo, s.d.

FIGUEIREDO, Jackson de. "Carta a um Jovem Romancista", in A Notícia, Rio de Janeiro, 3/set./1918.

"LAMPIÃO", in Correio de São Paulo. São Paulo, 27/jan./1934.

"LIVROS NOVOS. Lampião", in A Nação. Rio de Janeiro, 24/jan./1934.

LIMA, Alceu Amoroso. “Vida Literária. A Longa Estrada; O Lírio na Torrente", in O Jornal, Rio de Janeiro, 27/dez./1925.

PRATA, Ranulfo. O Triunfo. Rio de Janeiro, Revista dos Tribunais, 1918. . Lampião. Rio de Janeiro, Ariel, 1934. . Navios Iluminados. 1a ed. Rio de Janeiro, José Olympio, 1937.

RIBEIRO, João. "Dentro da Vida", in Imparcial. Rio de Janeiro, 16/maio/1922.

SODRÉ, Nelson Werneck. "Livros Novos. Navios Iluminados", in Correio Paulistano, São

Paulo, 20/fev./1938. 